\title{
La Corte Constitucional como agente del campo jurídico colombiano: la omisión legislativa de principios constitucionales"
}

\author{
Olga Cecilia González Noriega* \\ Recibido: 8 de abril de 2014. - Revisado: 8 de junio de 2014 . \\ Aprobado: 7 de septiembre de 2014.
}

\section{Resumen}

La inactividad o silencio de los órganos legislativos del Estado colombiano, frente a un mandato constitucional, conlleva desconocimiento de principios constituciones, valores y derechos de los administrados y, por ende, genera consecuencias jurídicas. En este sentido, ante el vacío normativo producido por la omisión legislativa absoluta o total, le corresponde al máximo órgano constitucional, como agente del campo jurídico, ejercer su capacidad de imponer con fuerza de autoridad sus pronunciamientos, crear una regla jurídica y aplicar en forma directa criterios axiológicos de la Carta Política, subsanando con ello la inactividad del legislador.

El objetivo general del presente artículo es identificar la naturaleza jurídica de la omisión legislativa y el papel que al respecto debe adelantar la Corte Constitucional. Lo anterior en aras de evidenciar cómo las autoridades legislativas deben ajustarse a los marcos trazados por el ordenamiento constitucional, y en especial, a las directrices de la Corte Constitucional, debiendo observar y acatar los mandatos previstos.

"El presente artículo es producto del proyecto de investigación titulado: La responsabilidad del Estado por el daño antijurídico de la falta de regulación o por la regulación legítima, para optar al título de doctor en Derecho de la Universidad Santo Tomas (sede Bogotá). Dicho proyecto de investigación ha sido financiado por la Universidad Industrial de Santander -UIS-, a través del apoyo económico que la citada Universidad otorgó a la autora del artículo.

2 "'Abogada y docente de la Universidad Industrial de Santander-UIS-. Magister en Hermenéutica Jurídica y Derecho, Universidad Industrial de Santander-UIS-.Correo electrónico: ogonzaleznoriega@ gmail.com 
El presente trabajo de investigación es de carácter cualitativo, en razón a que pretende obtener una comprensión profunda de los significados y definiciones del problema de investigación. Es pertinente anotar que las presentes lineas demandaron un trabajo de síntesis, el cual pretende resaltar la totalidad del contenido de una materia o tema, exponiendo sus partes principales y esenciales.

Palabras clave: omisión legislativa, campo jurídico, principios constitucionales.

\title{
The CONSTITUTIONAL COURT AS AgENT OF THE COLOMBIAN LEGAL FIELD: THE LEGISLATIVE OMISSION OF CONSTITUTIONAL PRINCIPLES
}

\begin{abstract}
Inactivity or silence of the legislative bodies of the Colombian State, against a constitutional mandate implies ignorance of constitutions principles, values and rights of the citizens and thus generates legal consequences. In this regard, given the legal vacuum created by the absolute or full legislative omission, it is up to the highest constitutional body, as agent of the legal field, exercise their ability to impose authority to force its decisions, a legal rule and applied as direct axiological criteria of the Constitution, thereby correcting the inactivity of the legislator.

The overall objective of this article is to identify the legal nature of the legislative omission and the role that the matter should advance the Constitutional Court. This in order to show how the legislative authorities must conform to the framework outlined by the constitutional order, and especially to the guidelines of the Constitutional Court and must observe and comply with the mandates provided.

This research is qualitative, because it aims to gain a deep understanding of the meanings and definitions of the research problem. It is pertinent to note that the present lines demanded a synthesis, which aims to highlight the entire contents of a subject or topic, exposing its main and essential parts.
\end{abstract}

Keywords: Omission legislative, legal field, constitutional principles. 


\section{A CORTE CONSTITUCIONAL COMO AGENTE DO CAMPO JURÍDico COLOMBIANO: A OMISSÃO LEGISLATIVA DE PRINCÍPIOS CONSTITUCIONAIS}

\section{Resumo}

A inatividade ou silêncio dos órgãos legislativos do Estado colombiano, frente a um mandato constitucional, implica em desconhecimento dos princípios constitucionais, valores e direitos dos administrados e, portanto, gera consequências jurídicas. Nesse sentido, diante do vazio normativo produzido pela omissão legislativa absoluta ou total, corresponde ao máximo órgão constitucional, como agente do campo jurídico, exercer sua capacidade de impor com força de autoridade seus pronunciamentos, criar uma regra jurídica e aplicar de forma direta critérios axiológicos da Carta Política, subsanando, dessa maneira, a inatividade do legislador.

O objetivo geral do presente artigo é identificar a natureza jurídica da omissão legislativa e o papel que a Corte Constitucional deveria exercer, a fim de evidenciar como as autoridades legislativas devem ajustar os marcos traçados pelo ordenamento constitucional, e em especial, às diretrizes da Corte Constitucional, devendo observar e acatar os mandatos previstos. Portanto, este trabalho é de caráter qualitativo, em razão de que pretende obter uma compreensão profunda dos significados e definições do problema de pesquisa. É pertinente anotar que as presentes linhas demandaram um trabalho de síntese, a qual pretende ressaltar a totalidade do conteúdo de uma matéria ou tema, expondo seus principais conceitos.

Palavras-chave: Omissão legislativa, campo jurídico, princípios constitucionais.

\section{Introducción}

La Constitución Política como norma fundamental del Estado consagra principios, valores y derechos de los ciudadanos, cuya efectividad debe ser objeto de desarrollo posterior por el legislador ordinario. Lo anterior en razón a que los principios, valores y derechos suponen normas incompletas que requieren de actuación posterior del órgano legislativo del poder público. A pesar de lo dispuesto, ocurre con frecuencia que el legislador guarda silencio u omite la obligación de darle desarrollo legal a estos postulados constitucionales, lo que genera como consecuencia que dicha deficiencia sea suplida por otro órgano del poder público, a fin de lograr que la norma constitucional cumpla su destino como norma jurídica suprema. 
En este orden de ideas, analizaremos el tratamiento que la Corte Constitucional, como máximo organismo encargado de la guarda y efectividad del ordenamiento constitucional, le ha dado a la omisión legislativa en sus dos formas: omisión parcial y omisión total.

El encargo que el ordenamiento constitucional hace al legislador para que legisle respecto de principios, valores y derechos, debe materializarse efectivamente a través de una ley. A pesar de lo anterior, se observa inactividad del legislador en la citada tarea, lo que ha generado como consecuencia que sea la Corte Constitucional quien se encargue de materializar los principios, derechos y valores constitucionales, en aras de subsanar el vacío dejado por el legislador y salvaguardar dichos preceptos constitucionales.

\section{Principios constitucionales}

La Constitución es la norma suprema del ordenamiento jurídico de un Estado, que vincula a todos los ciudadanos y órganos de poder, gobernantes y gobernados, razón por la cual es considerada como la norma fundamental de un Estado. Se ha entendido por supremacía de la Constitución, como "la cualidad política de toda Constitución, en cuanto a que esta es siempre, un conjunto de reglas que se tiene por fundamentales, es decir por esenciales, para la forma política" (Rodríguez, p. 136).

Atendiendo el problema de investigación planteado en este documento, es pertinente anotar que la Constitución ha sido concebida de tal manera que la parte orgánica de la misma, solo adquiere sentido y razón de ser como aplicación y puesta en obra de los principios, valores y derechos inscritos en la parte dogmática de la misma.

Los principios son bases ideológicas obligatorias que se configuran como mandatos de optimización que deben ser observados, toda vez que informan todo el ordenamiento jurídico colombiano, ya que son la guía a quienes aplican e interpretan la Constitución. Son normas fundamentales que sirven de justificación axiológica a otras normas y que para su aplicación deben concretarse para elaborar una regla que resulte idónea para resolver un caso particular (Guastini, 2010, p. 186). Para el efecto, ha sostenido la Corte Constitucional, que los principios constitucionales "consagran prescripciones jurídicas generales que suponen una delimitación política y axiológica reconocida y, en consecuencia, restringen el espacio de interpretación” (Corte Constitucional, sentencia T-778 de 1992). De conformidad con lo dispuesto, 
sin lugar a equívocos, es importante resaltar que los principios fundamentales del Estado como parte de la Constitución, son una pauta de interpretación; son un deber ser del que se deriva un espacio de discrecionalidad legal y judicial.

En nuestro Estado de Derecho y dentro del desarrollo de la democracia constitucional, se ha consolidado el poder del órgano legislativo, depositario de la legitimidad popular, junto con el control constitucional, órgano que ha sido eficaz en la defensa de los derechos de los ciudadanos y de los principios. Al respecto, es importante resaltar que ante la falta de regulación legal, en especial de los principios constitucionales, la legislación ha perdido su valor predominante en el ordenamiento jurídico, y que ello ha abierto espacio a la aplicación directa de los principios constitucionales por parte de los jueces de la República.

\section{La omisión legislativa}

La Constitución Política como Ley fundamental, obliga y vincula a todos los ciudadanos y órganos del poder público, y como consecuencia de ello, todo el ordenamiento jurídico debe someterse a ella para que no pierda su valor jurídico; lo que supone que el orden jurídico del Estado emana de la Constitución y es la fuente del sistema jurídico.

Al ser la Carta Política norma fundamental, su infracción afecta la supremacía de la misma; de tal suerte que se vulnera la carta, tanto por la expedición de una ley contraria a su contenido como por la omisión del legislativo al no dar alcance normativo a los ítems axiológicos constitucionales que lo requieren. Atendiendo esta última perspectiva, frente a la omisión en el desarrollo de principios constitucionales a través de la ley, se han desarrollado diferentes teorías en cuanto a la aplicación directa de la norma constitucional. Una de ellas, es la tesis expuesta por el profesor García de Enterría, quien parte de considerar a la Constitución como una "norma jurídica" y sostiene que el ordenamiento constitucional consagra preceptos de aplicación inmediata o directa, cuando ella regula en forma suficiente un principio, por lo que su aplicación directa quedaría condicionada a la aplicación de los jueces, y con ello se impediría que una norma constitucional quedara condicionada a la reglamentación por parte del legislador.

Ahora bien, existe en la Constitución preceptos que son de obligatorio desarrollo por parte del legislador; esto es, normas de eficacia limitada que, dada la provisión implícita o explícita en ella contenida, resultan de obligatorio y concreto desarrollo 
para su eficacia plena, eficacia entendida como la conformidad o adecuación de la conducta de los destinatarios con lo que la norma prescribe (Segura, 1991, p. 143). Son normas de carácter imperativo que, para completar su eficacia, requieren de un desarrollo ulterior, de obligación del órgano legislativo, que consiste en la expedición de una Ley que desarrolle el respectivo precepto constitucional. En este sentido, es la misma Constitución la que le impone al órgano legislativo una obligación de hacer un mandato de ejercicio expreso, porque es una competencia indubitable del legislador, quien no tiene la opción de elegir si expide o no una norma concreta y determinada que desarrolle el postulado axiológico constitucional, sino que existe el mandato expreso de expedirla.

Atendiendo lo dispuesto en líneas anteriores, es pertinente anotar que el silencio del legislador -principal o subsidiario- puede ser lesivo del ordenamiento constitucional, lo que hace necesario que dicho silencio afecte los deberes que la misma Constitución le impone, y que mantenga o cree situaciones jurídicas contrarias a la Constitución.

Ha sostenido la Corte Constitucional que:

Las normas constitucionales no deben correr el riesgo de quedarse escritas, porque ello llevaría indefectiblemente a la pérdida de su valor normativo y de los fines inspiradores del ordenamiento constitucional. Los fines esenciales del Estado (artículo 2 C.P) imponen al órgano legislativo el deber de llevar a cabo, en un plazo razonable, las reformas y desarrollos legales necesarios para garantizar la efectividad de las decisiones del constituyente... (Corte Constitucional. Sentencia C-188 de 1996).

Así las cosas, la Constitución Política puede ser incumplida de dos formas: por acción, cuando el legislador expide una norma abiertamente contraria a los preceptos constitucionales; y por omisión, cuando el legislador omite la orden constitucional para desarrollar preceptos constitucionales de orden axiológico. Sobre este aspecto sostiene el profesor Víctor Bazán que "la Constitución se vulnera no solamente cuando se hace lo que ella prohíbe hacer, sino también cuando se deja de hacer lo que ella manda que se haga" (Bazán, 1997, p. 3).

Las omisiones legislativas se derivan del no cumplimiento de disposiciones constitucionales legislativas; es decir, del no cumplimiento de normas que de forma 
concreta vinculan y obligan al legislador a la creación de medidas legislativas que concreten y hagan viables los postulados axiológicos de la Carta Política.

Se ha considerado la omisión legislativa como "la falta de desarrollo por parte del Poder Legislativo, durante un tiempo excesivamente largo, de aquellas normas constitucionales de obligatorio y concreto desarrollo de forma tal que se impide su eficaz aplicación” (Fernández, 1997, p. 81).

El tratadista español Villaverde Menéndez (1997, p. 94), señala que se constituye omisión legislativa cuando el silencio genera o conserva situaciones en el ordenamiento jurídico no queridas por la Constitución, impidiendo así una situación jurídica impuesta por la norma constitucional. Implica la omisión legislativa un desconocimiento o desacato producido por la falta total de desarrollo legislativo de un mandato constitucional o por el desarrollo parcial de lo que dispone la Carta Fundamental.

\subsection{Omisión legislativa relativa y absoluta}

La omisión legislativa puede ser absoluta o relativa (conocida también como: omisión total o parcial). Es absoluta cuando la norma que el legislador debe expedir no existe, hecho que afecta el desarrollo y aplicación del texto constitucional; y produce un silencio total del legislador sobre una materia determinada cuya regulación ha sido impuesta por una norma constitucional. Es relativa cuando el legislador expide la norma, pero es deficiente e incompleta, dejando de regular algunas hipótesis, deja lagunas en la legislación o excluye la aplicación de un derecho a grupos de población, situación que niega la protección de sus intereses. En esta clase de omisión, aunque la norma ha sido expedida por el órgano competente, sus falencias le impiden alcanzar el perfeccionamiento del mandato constitucional.

La Corte ha admitido la teoría de la omisión legislativa bajo el siguiente argumento:

La constitución puede ser vulnerada tanto por medio de la acción del legislador como por vía de omisión legislativa, esto es, cuando el legislador estando obligado a realizar una determinada acción-regulación- no lo hace (Fernández, 1997, p. 81).

Sin embargo, el tratamiento dado por el máximo órgano constitucional a la omisión legislativa ha sido diferente tratándose de omisión legislativa relativa u omisión legislativa absoluta. 
De conformidad con la Sentencia C-1004 -07, la Corte Constitucional es competente para conocer las omisiones legislativas relativas, toda vez que estas tienen efectos jurídicos que pueden presentar una oposición objetiva y real con la Constitución, que se puede verificar a través de una confrontación de los mandatos acusados y las disposiciones superiores. De ahí que admite la procedencia de la acción pública de constitucionalidad, a efecto de que se declare la omisión legislativa relativa y, en consecuencia, se expida una de exequibilidad condicionada que incorpore el supuesto de hecho que ha sido excluido por el legislador. En este sentido, admite la Corte que procede el control de constitucionalidad, siempre y cuando se den dos condiciones:

i) El juicio de inexequibilidad requiere la concurrencia de una norma frente a la cual se predique la omisión; y (ii) la misma debe excluir un ingrediente, condición normativa o consecuencia jurídica que a partir de un análisis inicial o de una visión global de su contenido, permita concluir que su consagración normativa resulta esencial e indispensable para armonizar el texto legal con los mandatos de la Carta Fundamental (Corte Constitucional, sentencia C-423/06).

Asimismo la Corte Constitucional, ha señalado que para proceder al examen de constitucionalidad de una disposición jurídica demandada, por haber incurrido el legislador en omisión legislativa relativa, deben darse los siguientes requisitos de orden normativo:

(i) Que exista una norma sobre la cual se predique necesariamente el cargo; (ii) que la misma excluya de sus consecuencias jurídicas aquellos casos que, por ser asimilables, tenían que estar contenidos en el texto normativo cuestionado, o que el precepto omita incluir un ingrediente o condición que, de acuerdo con la Constitución, resulta esencial para armonizar el texto legal con los mandatos de la Carta; (iii) que la exclusión de los casos o ingredientes carezca de un principio de razón suficiente; (iv) que la falta de justificación y objetividad genere para los casos excluidos de la regulación legal una desigualdad negativa frente a los que se encuentran amparados por las consecuencias de la norma; y (v) que la omisión sea el resultado del incumplimiento de un deber específico impuesto por el constituyente al legislador (Corte Constitucional, sentencia C-185 de 2002). 
De otro lado, y para efecto de subsanar las omisiones constitucionales relativas, la Corte Constitucional ha utilizado dos tipos de sentencia:

- Sentencia integradora: aquellas que declaran la ilegitimidad constitucional de la previsión omitida que debería haber sido prevista por la ley para que esta fuera constitucional. La Corte en estas sentencias no anula la norma acusada, sino que le agrega un contenido que la hace constitucional (Olano, 2004).

- Sentencia interpretativa o condicionada: con estas sentencias la Corte excluye la interpretación o interpretaciones que no se encuentran conforme a la Constitución. Ellas se fundamentan en dos principios: el de interpretación de la ley conforme a la Constitución y el principio de la conservación del derecho (Corte Constitucional. Sentencia C-038 de 2006. Dr. Humberto Sierra Porto).

Con esta tipología de sentencias, se considera que la citada Corte evita los vacíos presentados en el ordenamiento jurídico, conservando el precepto impugnado vigente y garantizando la supremacía de la Constitución.

Ahora, en cuanto a la omisión legislativa absoluta, no se considera la Corte competente, es decir, cuando el legislador ha adoptado una posición inactiva frente a un postulado constitucional que, para su aplicación requiere ser desarrollado. Al presentarse la omisión absoluta por la falta total de regulación, no es procedente la acción pública de inconstitucionalidad, que evalúa si el legislador al actuar ha vulnerado o no un canon constitucional; al no existir actuación, no hay acto que comparar con las normas superiores y, por lo tanto, no existe acto que pueda ser sujeto de control. Por esta razón, la Corte Constitucional carece de competencia para conocer de demanda de inconstitucionalidad cuando se presenta la omisión legislativa absoluta. Ha sostenido la Corte que:

(...) No tiene competencia para conocer acerca de demandas dirigidas en contra de omisiones legislativas absolutas. Para ello se ha sustentado en considerar que (i) no es metodológicamente posible el examen de constitucionalidad en estos casos por la carencia de norma susceptible de control, (ii) es indispensable que la demanda de inconstitucionalidad recaiga sobre un texto real y no simplemente deducido por el actor o implícito, (iii) la declaración de inexequibilidad total o parcial de una disposición legislativa requiere previamente definir si existe una oposición definitiva y verificable entre lo que dispone el precepto acusado y lo que manda la Constitución. En la sentencia C-543 de 1996 sostuvo este Tribunal: lo que se pretende mediante 
la acción de inconstitucionalidad es evaluar si el legislador al actuar ha vulnerado o no los distintos cánones que conforman la Constitución. Por esta razón hay que excluir de esta forma de control el que se dirige a evaluar las omisiones legislativas absolutas: si no hay actuación no hay acto que comparar con las normas superiores; si no hay actuación, no hay acto que pueda ser sujeto de control. La Corte carece de competencia para conocer de demandas de inconstitucionalidad por omisión legislativa absoluta. En el mismo sentido sostuvo en la sentencia C-146 de 1998: (...) son inconstitucionales por omisión aquellas normas legales que por no comprender todo el universo de las hipótesis de hecho idénticas a la regulada, resultan ser contrarias al principio de igualdad. Pero la omisión legislativa pura o total, no es objeto del debate en el proceso de inexequibilidad, puesto que este consiste, esencialmente, en un juicio de comparación entre dos normas de distinto rango para derivar su conformidad o discrepancia. Luego el vacío legislativo absoluto no puede ser enjuiciado en razón de la carencia de objeto en uno de los extremos de comparación.

En otro de sus fallos sostuvo que:

Finalmente, la ausencia de regulación de una determinada materia no necesariamente puede ser objeto de reproche constitucional, ya que los silencios del Legislador en determinados casos son expresiones de su voluntad (Corte Constitucional, sentencia C-038/06. Criterio reiterado en sentencia C-831 de 2007).

\section{La Corte Constitucional: agente del campo jurídico productora de normas}

Es preciso no olvidar que la modulación de los efectos de la sentencia de constitucionalidad es una consecuencia de la función que tiene la Corte Constitucional como guardiana de la integridad y supremacía de la Constitución Política. Sobre el particular ha dicho la Corte:

El juez constitucional cuenta con varias alternativas al momento de adoptar una determinación, ya que su deber es pronunciarse de la forma que mejor permita asegurar la integridad del texto constitucional, para lo cual puede modular los efectos de sus sentencias, ya sea desde el punto de vista del contenido de la decisión, ya sea desde el punto de vista de sus efectos temporales (Caballero, 2007, p. 529). 
La necesidad de modular las sentencias, ha dicho la Corte, "resulta de las tensiones valorativas implícitas en todo texto constitucional y de la dinámica misma del control judicial de la constitucionalidad de las leyes". A través de esta técnica, la Corte Constitucional puede en la misma sentencia, señalar sus efectos. Y para tal fin la Corte ha planteado la siguiente metodología:

Los efectos concretos de la sentencia de inexequibilidad dependerán entonces de una ponderación, frente al caso concreto, del alcance de dos principios encontrados: la supremacía de la Constitución -que aconseja atribuir a la decisión efectos ex tunc, esto es retroactivos- y el respeto a la seguridad jurídica-que, por el contrario, sugiere conferirle efectos ex nunc, esto es únicamente hacia el futuro- (Corte Constitucional. Sentencia C-619 de 2003).

La omisión legislativa relativa o parcial se sanea a través de la acción pública de inconstitucionalidad, lo que ha permitido que el órgano de control constitucional asuma la creación de normas (incorporación de una norma al ordenamiento jurídico), por medio de la técnica de modulación de los efectos de sus sentencias, generando como consecuencia que la Corte Constitucional se haya constituido en un legislador positivo; en aras de la defensa de la fuerza normativa de la Constitución que prevalece sobre la autonomía legislativa. No ocurre lo mismo con la omisión legislativa absoluta en la que se abstiene el órgano constitucional de pronunciarse, razón por la cual se mantiene el vacío normativo.

La Constitución Política tiene una eficacia normativa y directa que vincula a todos los poderes constituidos -incluso al órgano constitucional- y los conmina a respetarla y observarla, para evitar que sea incumplida. Siendo imperioso garantizar la efectividad de los principios consagrados en el ordenamiento constitucional, el incumplimiento, por parte del órgano legislativo de su función de desarrollarlos y hacerlos eficaces, conlleva consecuencias jurídicas. Las implicaciones que conlleva la omisión de regular un principio constitucional, que lo hace ineficaz, dan lugar a que en la práctica deba hacerse una adecuada ponderación de la realidad y del contexto en el que se produce. Siempre debe existir un mecanismo que permita hacer efectivos los derechos fundamentales que consagra el ordenamiento constitucional, ante la ausencia de norma y la consecuente afectación de un derecho fundamental y del principio de igualdad dentro del estado social y derecho democrático. 
Siendo así, frente a la vulneración de una concreta obligación de desarrollo de una determinada norma constitucional por el órgano legislativo, que conlleva en la mayoría de los casos el incumplimiento de los postulados constitucionales y, ante la ausencia de norma positiva que los desarrolle, el órgano constituyente, como uno de los actores principales del campo jurídico, tiene la capacidad de generar pronunciamientos a través de sentencias con "poder de imponerse con fuerza de autoridad y convertirse en regla” (Bourdieu, 2000, p. 20).

Los tribunales constitucionales deben utilizar todos los principios legales y constitucionales existentes, con el fin de lograr la materialización de los principales valores constitucionales, como el de la igualdad, la justicia, la inclusión social. De ahí que la actividad constitucional es una forma de lograr la inclusión y la emancipación social y política.

En el campo jurídico se enfrentan permanentemente diversas concepciones sobre la forma de entender el derecho y sobre los principios que deberían regirlo. Enfrentamiento limitado por la idea de "Competencia Jurídica", que excluye a quienes no tienen autoridad ni la capacidad para dar conceptos adecuados que permitan un debate jurídico. Entonces el poder en el campo jurídico equivale a la posición de los agentes y de las instituciones en el espacio social complejo.

Queda claro que la autonomía del campo jurídico es relativa: para Bourdieu las fuerzas de los diferentes agentes en el campo jurídico deben ser puestas en relación con la posición general que ocupa dentro del campo de poder del espacio social. Para Bourdieu, uno de los agentes del campo jurídico, son precisamente los magistrados, quienes junto con los doctrinantes y actores políticos aportan a la producción e interpretación del cuerpo de normas jurídicas, los que se convierten en legisladores y creadores de normas (Moreno, p. 63).

El máximo Tribunal Constitucional -la Corte Constitucional- como agente del campo jurídico, al crear la norma que llena el vacío dejado por el legislador, contribuye a la producción e interpretación del corpus de las reglas jurídicas; en forma explícita, cuando el constituyente indica al legislador expresamente que se debe emitir una ley; o implícita cuando el constituyente no disponga que una ley regulará la materia por ser necesaria la intervención del legislador para su adecuada aplicación operativa (casos en que se aplica el principio de reserva legal).

Este modo de proceder del Tribunal Constitucional refleja el papel que desempeña y el lugar que ocupa dentro del campo jurídico colombiano, actuación que en el contexto de un formalismo exacerbado ha suscitado un reparo frente 
a la legitimación política que le sustenta. Empero, el carácter vinculante de las disposiciones normativas constitucionales obliga a la Corte en tal sentido, razón por la cual es la misma Constitución Política la que determina quién es su máximo intérprete y, por ende, el determinador de lo que sea o no derecho vigente. Así, la Corte Constitucional como operador de justicia, aplica en forma directa los principios constituciones.

Con este proceder, se subsana la inactividad del legislador que conlleva la ausencia de eficaz aplicación de las normas constitucionales de obligatorio y concreto desarrollo, y que impide que los destinatarios de dicha norma la cumplan, no porque no estén de acuerdo con su contenido, sino porque no existe regulación que les permita cumplirla.

Como sostiene el profesor Markus González:

(...) Con ello el sistema de fuentes del derecho se modifica, porque se atribuye fuerza vinculante y carácter de fuente de derecho a la jurisprudencia de la Corte Constitucional; se transforma el equilibrio de poderes, porque, de una parte se acepta que la Corte Constitucional no puede concebirse únicamente como un legislador negativo, sino como un órgano activo, que colabora con el Legislativo y el Ejecutivo en la labor de producción de normas (González, 2000, p. 149).

\section{Conclusiones}

La teoría clásica redivisión de los poderes en la actualidad es objeto de matización cuando la Corte Constitucional debe dar alcance a los principios constitucionales por no hacerlo el legislador.

Si bien las sentencias aditivas e integradoras que puede emitir la Corte Constitucional cuando efectúa control de constitucionalidad, han sido objeto de todas las críticas sobre su papel en el ordenamiento jurídico colombiano; a pesar de ello, son las que han permitido materializar los postulados axiológicos de la Constitución Política, y en especial de los principios constitucionales.

A pesar de la importancia de los principios constitucionales en el ordenamiento jurídico colombiano, se observa la ausencia del Congreso de la Republica en su labor de dar alcance a los mismos, lo que le ha permitido a la Corte Constitucional 
fortalecer su papel en la estructura orgánica del estado, emitiendo las respectivas providencias judiciales que otorguen alcance a dichos postulados.

La omisión legislativa se constituye en una clara vulneración a los postulados elementales de un estado social de derecho, que supone la garantía del reconocimiento de los postulados constitucionales de orden axiológico.

\section{Referencias}

Bazán, V. (1997). Inconstitucionalidad por omisión. Bogotá: Editorial Temis. . (2010). Derecho Procesal Constitucional Americano y Europeo. Tomos I y II. Buenos Aires: Abeledo Perrot.

Bernal, C. (2005). El Derecho de los derechos. Bogotá: Universidad Externado de Colombia. Bourdieu, P. (2008). La fuerza del Derecho. Bogotá: Ediciones Uniandes. Constitución Política de Colombia. Legis.

Diccionario Jurídico Espasa. (1999). Madrid: Espasa Calpe S. A.

Fernández, J. J. (s.f.). La inconstitucionalidad por omisión. Teoria General. Derecho Comparado. El caso Español. España: Civitas. S. A.

Guastini, R. (2010). Los principios constitucionales en tanto fuente de perplejidad. En Bazán Víctor. Derecho Procesal Constitucional Americano y Europeo, 1, 186. Buenos Aires: Abeledo Perrot.

Moreno, Á., y Ramírez, J. E. (2006). Introducción elemental a la obra de Pierre Bourdieu. Bogotá.

. (s.f.). Sociología del campo jurídico en Colombia. Relaciones y perspectivas. Instituto

Latinoamericano de Altos Estudios.

Peña, A. M. (1997). La garantía en el estado constitucional de Derecho. Madrid: Editorial Trotta. Segura, M. (1991). Teoría del Derecho. Madrid: Centro de Estudios Ramón Areces.

Sentencia T-778 de junio 5 de 1992. Mp. Dr. Ciro Angarita Barón.

Sentencia C-188 de 1996.

Sentencia C-1004 de 2007.

Sentencia C-423 de 2006.

Sentencia C-185 de 2002.

Sentencia C-038 de 2006.

Sentencia C-619 de 2003.

Sentencia C-055 de 1996.

Sentencia C-543 de 1996.

Sentencia C-504 de 1995. 
Sentencia C-146 de 1998

Sentencia C-038 de 2006.

Sentencia C-831 de 2007.

Sierra, O. (1998). Concepto y tipos de Ley en la Constitución Colombiana. Bogotá: Universidad Externado de Colombia.

Vidal, J. (1996). Derecho Constitucional General Instituciones Políticas Colombianas. Bogotá: Universidad Externado de Colombia. Universidad Nacional de Colombia.

Villaverde, I. (1997). La inconstitucionalidad por omisión. Madrid: McGraw-Hill.

Villegas, M., y Rodríguez, C. (s.f.). Derecho y Sociedad en América Latina. Un debate sobre los estudios jurídicos críticos. ILSA: Universidad Nacional de Colombia. 